\title{
A pilot study: Screening target miRNAs in tissue of nonsyndromic cleft lip with or without cleft palate
}

\author{
SHAN WANG ${ }^{1}$, CHANGSHENG SUN $^{2}$, YAN MENG ${ }^{1}$, BING ZHANG $^{2}$, XIN WANG $^{1}$, \\ YANGUO $\mathrm{SU}^{1}$, LEI SHI $^{1}$ and ERYANG ZHAO ${ }^{1}$ \\ Departments of ${ }^{1}$ Oral Pathology and ${ }^{2}$ Oral and Maxillofacial Surgery, \\ The First Affiliated Hospital, Harbin Medical University, Harbin, Heilongjiang 150001, P.R. China
}

Received August 25, 2015; Accepted January 26, 2017

DOI: $10.3892 / \mathrm{etm} .2017 .4248$

\begin{abstract}
Nonsyndromic cleft lip with or without cleft palate (NSCLP) has been recognized as a condition resulting from a combination of environmental and genetic factors. Studies have demonstrated that microRNAs (miRNAs) are involved in embryonic development. However, few studies have focused on screening potential target miRNAs in human NSCLP tissue. Using microarray-based miRNA expression profiling, miRNA expression was compared in tissue samples from 4 NSCLP patients and 4 healthy control subjects. Two hundred and fifty-four miRNAs were found to be differentially expressed. Changes in Homo sapiens (hsa)-miR-24-3p, hsa-miR-27b-3p, hsa-miR-205-5p, hsa-miR-1260b and hsa-miR-720 were of particular interest with respect to Wnt signaling (fold-changes were $12.5,12.2,12.1,12.3$ and 10.5 , respectively; $\mathrm{P}<0.005$ for all). The levels of hsa-miR-24-3p, hsa-miR-1260b and hsa-miR-205-5p were higher in tissues from NSCLP patients than in those from controls according to PCR analysis. Hsa-miR-24-3p, hsa-miR-1260b and hsa-miR-205-5p may be candidate miRNAs involved in the etiology of NSCLP via Wnt signaling.
\end{abstract}

\section{Introduction}

Nonsyndromic cleft lip with or without cleft palate (NSCLP) is one of the most common human craniofacial malformations. The incidence is 1.82/1,000 live births in China, and the worldwide overall incidence of oral clefts is estimated to be $1.43 / 1,000$, with a wide variability among ethnic groups and regions (1). NSCLP is a complex disorder that does not

Correspondence to: Professor Eryang Zhao, Department of Oral Pathology, The First Affiliated Hospital, Harbin Medical University, 23 Youzheng Street, Harbin, Heilongjiang 150001, P.R. China E-mail: zhaoeryang1956@yeah.net

Abbreviations: NSCLP, nonsyndromic cleft lip with or without cleft palate; miRNAs, microRNAs

Key words: miRNA, cleft lip, cleft palate, human follow normal Mendelian patterns of inheritance; rather, NSCLP exhibits etiological heterogeneity wherein genetic and environmental factors may predispose patients to orofacial clefts (2-4). In addition, gene-gene and/or gene-environment interactions may contribute to clefting (5-7). The etiopathogenesis of clefts has been widely studied but remains poorly understood.

Mature microRNAs (miRNAs), which are small, naturally occurring non-coding RNAs, inhibit messenger RNA and act as negative regulators of gene expression. miRNAs are crucial for the proper spatiotemporal development of various tissues and organs (8-11). The roles of miRNAs in cellular proliferation and differentiation as well as embryonic development are gradually becoming clear (12). In addition, there is evidence that miRNAs may be required for craniofacial development (13), and Eberhart et al (14) demonstrated that the microRNA Mirn140 negatively regulates platelet-derived growth factor (PDGF) signaling during palatal development, and provided a mechanism for how the disruption of PDGF signaling causes palatal clefting in zebrafish.

Despite the acknowledged function of miRNAs in development and their importance in disease, as well as the fact that miRNAs are a unique means of modulating signaling pathways such as Wnt and transforming growth factor- $\beta$ (15-18), little is known with regard to the involvement of miRNAs in regulating NSCLP. Research on the above issue is still in the early stages, at which the problem of selecting appropriate samples and screening miRNAs in human tissues require to be solved. It represents a novel approach to elucidating the pathogenesis of NSCLP with regard to miRNAs. Certain general principles require establishment as follows: i) Tissue was selected over blood, as tissue provides RNA of higher quality and quantity. This is likely to reduce the stress and potential side effects associated with invasive sample collection and thus, greatly facilitate participant recruitment for the study. ii) Umbilical samples were used as control tissue. NSCLP is a congenital deformity caused by abnormal facial development during gestation and forms in embryos at 6-8 gestational weeks (19). The umbilical cord develops from and contains remnants of the yolk sac and allantois (and is therefore derived from the zygote), which is involved in the whole embryonic process. Healthy umbilical cords were used in the present study. This not only takes into consideration the fact that NSCLP tissues 
collected were more than one year apart from the timing when clefts were forming in utero, but also allows the miRNA to be synchronized with spatiotemporal characteristics in development. iii) Patients aged 3-24 months were selected as these patients can endure plastic surgery according to Chinese standards (20).

The expression of 1,800 unique human miRNAs was profiled in four NSCLP and 4 normal umbilical cord samples using locked nucleic acid-based oligonucleotide microarrays and several miRNAs that may be associated with the Wnt signal pathway were screened.

\section{Materials and methods}

Specimen collection. The NSCLP samples used in the present study were obtained from four patients with NSCLP from the Department of Oral and Maxillofacial Surgery (Hospital of Stomatology, the First Affiliated Hospital, Harbin Medical University, Harbin, China) and were tissues that were not re-used in plastic surgery. The 4 umbilical cord tissues (used as the control) were obtained from the Department of Obstetrics and Gynecology at the First Affiliated Hospital of Harbin Medical University from July 2012 to August 2012. Control umbilical cord tissues were donated by healthy gravidae without systemic disease, clefts or family history thereof. The samples were flash-frozen in liquid nitrogen and stored at $-80^{\circ} \mathrm{C}$ until RNA extraction. Of these samples, 8 were used for miRNA microarray analysis and 8 were used for reverse transcription-quantitative polymerase chain reaction (RT-qPCR) analysis. The NSCLP cases were classified as bilateral NSCLP, unilateral NSCLP, right unilateral NSCLP and left unilateral NSCLP. The clinical data of the patients are shown in Table I. Written consent for tissue donation (for research purposes) was obtained from the patients or their parents prior to tissue collection and the protocol was approved by the Institutional Review Board of the First Affiliated Hospital of Harbin Medical University (Harbin, China).

miRNA microarray. The 7th generation miRCURY ${ }^{\mathrm{TM}}$ LNA Array (v.18.0; Exiqon, Inc, Woburn, MA, USA) contains 3,100 capture probes, covering all the human miRNAs annotated in miRBase 18.0 as well as all viral miRNAs associated with these. In addition, this array contains capture probes for 25 miRPlus $^{\mathrm{TM}}$ human miRNAs.

RNA extraction. Total RNA was isolated using TRIzol (Invitrogen; Thermo Fisher Scientific, Inc., Waltham, MA, USA) and the miRNeasy Mini kit (Qiagen, Hilden, Germany) according to the manufacturers' instructions, efficiently recovering all RNA species including miRNA. RNA quality and quantity was measured using a NanoDrop spectrophotometer (ND-1000; Thermo Fisher Scientific, Inc.) and RNA integrity was determined by gel electrophoresis.

RNA labeling. After RNA isolation from the samples, the miRCURY ${ }^{\mathrm{TM}} \mathrm{Hy}^{\mathrm{TM}} / \mathrm{Hy}^{\mathrm{TM}}$ Power labeling kit (Exiqon, Inc.) was used according to the manufacturer's instructions for miRNA labeling. One microgram of each sample was 3 '-end-labeled with the $\mathrm{Hy} 3^{\text {тм }}$ fluorescent label, using T4 RNA ligase and the following procedure: RNA in $2.0 \mu \mathrm{l}$ water
Table I. Clinical background of the 4 Han Chinese NSCLP patients.

\begin{tabular}{lcll}
\hline & $\begin{array}{c}\text { Age } \\
\text { Gender }\end{array}$ & \multicolumn{1}{c}{ Classification } & \multicolumn{1}{c}{ Tissue type } \\
\hline Female & 3 & Right unilateral NSCLP & Lip mucosa \\
Male & 3 & Left unilateral NSCLP & Lip mucosa \\
Female & 24 & Bilateral NSCLP & Palatine mucosa \\
Male & 18 & Left unilateral NSCLP & Palatine mucosa \\
\hline
\end{tabular}

NSCLP, nonsyndromic cleft lip with or without cleft palate.

was combined with $1.0 \mu \mathrm{l}$ CIP buffer and CIP (Exiqon). The mixture was incubated for $30 \mathrm{~min}$ at $37^{\circ} \mathrm{C}$ and the reaction was terminated by incubating at $95^{\circ} \mathrm{C}$ for $5 \mathrm{~min}$. Subsequently, $3.0 \mu \mathrm{l}$ labeling buffer, $1.5 \mu \mathrm{l}$ fluorescent label (Hy3 $\left.3^{\mathrm{TM}}\right), 2.0 \mu \mathrm{l}$ dimethyl sulfoxide and $2.0 \mu$ labeling enzyme were added to the mixture. The labeling reaction was then incubated for $1 \mathrm{~h}$ at $16^{\circ} \mathrm{C}$ and terminated by incubating at $65^{\circ} \mathrm{C}$ for $15 \mathrm{~min}$.

Array hybridization. After stopping the labeling procedure, the Hy $3^{\mathrm{TM}}$-labeled samples were hybridized to the miRCURY ${ }^{\mathrm{TM}}$ LNA Array (v.18.0; Exiqon, Inc.) according to the instructions from the array manual. The total $25-\mu 1$ mixture containing the $\mathrm{Hy} 3^{\mathrm{TM}}$-labeled samples was added to $25 \mu \mathrm{l}$ hybridization buffer, denatured for $2 \mathrm{~min}$ at $95^{\circ} \mathrm{C}$ and then incubated on ice for $2 \mathrm{~min}$. Subsequently, the mixture was hybridized to the microarray for $16-20 \mathrm{~h}$ at $56^{\circ} \mathrm{C}$ in a 12 -Bay Hybridization System (Nimblegen Systems Inc., Madison, WI, USA), which provided an active mixing action and constant incubation temperature to improve hybridization uniformity and enhance the signal. Following hybridization, the slides were washed several times using a Wash Buffer kit (Exiqon, Inc.) and dried by centrifugation for $5 \mathrm{~min}$ at $127.44 \mathrm{x}$. The slides were then scanned using an Axon GenePix 4000B microarray scanner (Axon; Molecular Devices, LLC, Sunnyvale, CA, USA).

miRNA target prediction. MicroCosm Targets Version5 (http://www.ebi.ac.uk/enright-srv/microcosm/htdocs/targets/v5/), formerly miRBase Targets, Miranda (http://www.microrna. org/microrna/home.do), which contains the target information for the hg19, mm9 and RN34 miRNAs, and TargetScan version 6.2 (http://www.targetscan.org/vert_60/), which provides information about human and mouse miRNA, were used to analyze potential target genes for the deregulated miRNAs.

$R T$ - $q P C R$. To confirm the results obtained by miRNA profiling, the expression of selected miRNAs was measured using RT-qPCR according to standard protocols on an Applied Biosystems 7700 HT Sequence Detection System (Thermo Fisher Scientific, Inc.). In brief, complementary (c)DNA was synthesized from total RNA using gene-specific primers (Table II). Reverse transcriptase reactions contained 800 ng RNA, $1 \mu \mathrm{mol} / 1$ stem-loop RT primer, 10X RT buffer, $2.5 \mathrm{mmol} / \mathrm{l}$ of each of the dNTPs, $200 \mathrm{U} / \mu 1$ MultiScribe reverse transcriptase and $40 \mathrm{U} / \mu 1 \mathrm{RNase}$ inhibitor. The $20-\mu \mathrm{l}$ reactions were incubated for $30 \mathrm{~min}$ at $16^{\circ} \mathrm{C}, 40 \mathrm{~min}$ at $42^{\circ} \mathrm{C}$, and $5 \mathrm{~min}$ 
Table II. Oligonucleotide primers used in the present study.

\begin{tabular}{lll}
\hline $\begin{array}{l}\text { Primer } \\
\text { set name }\end{array}$ & \multicolumn{1}{c}{$\begin{array}{c}\text { Reverse-transcriptase } \\
\text { reaction primer (5'-3') }\end{array}$} & \multicolumn{1}{c}{ PCR primer (5'-3') } \\
\hline U6 & CGCTTCACGAATTTGCGTGTCAT & $\begin{array}{l}\text { F: GCTTCGGCAGCACATATACTAAAAT } \\
\text { R: CGCTTCACGAATTTGCGTGTCAT }\end{array}$ \\
hsa-miR-1260b & GSC: GGAATCCCACCACTGC \\
& GGCAATTGCAGTGCGTGTCGTGGAGTC & R: TGCGTGTCGTGGAGTC \\
hsa-miR-24-3p & GTCGTATCCAGTGCGTGTCGTGGAGTC & GSP: GGGTGGCTCAGTTCAGC \\
hsa-miR-27b-3p & GGCAATTGCACTGGATACGACCTGTTC & R: CAGTGCGTGTCGTGGAG \\
& GTCGTATCCAGTGCGTGTCGTGGAGTC & GSP: GGGGGTTCACAGTGGCTAAG \\
hsa-miR-205-5p & GGCAATTGCACTGGATACGACGCAGAA & R: GTGCGTGTCGTGGAGTCG \\
& GTCGTATCCAGTGCGTGTCGTGGAGTCG & GSP: CGTCCTTCATTCCACCG \\
& GCAATTGCACTGGATACGACCAGACT & R: CAGTGCGTGTCGTGGAGT
\end{tabular}

F, forward; R, reverse; GSP, gene-specific primer; PCR, polymerase chain reaction; miR, microRNA; hsa, Homo sapiens.

at $85^{\circ} \mathrm{C}$ and then were held at $4{ }^{\circ} \mathrm{C}$. The $10-\mu 1$ PCR reaction mixture included $2 \mu \mathrm{l}$ RT product, $2 \mu 1$ 2X SYBR Green PCR master mix (Thermo Fisher Scientific, Inc.) and $1 \mu 1$ primers (Table II). Reactions were incubated in a 384-well optical plate at $95^{\circ} \mathrm{C}$ for $10 \mathrm{~min}$, followed by 40 cycles of $95^{\circ} \mathrm{C}$ for $10 \mathrm{sec}$ and $60^{\circ} \mathrm{C}$ for $1 \mathrm{~min}$. U6 small nuclear RNA was used as an internal control to normalize RNA input. The fold-change was calculated using the $2^{-\Delta \Delta \mathrm{Cq}}$ method (21), where $\mathrm{Cq}$ is defined as the fractional cycle number at which the fluorescence passes the fixed threshold, and presented as the fold-expression change in NSCLP tissues relative to their corresponding normal tissues after normalization to the endogenous control. All experiments were performed in triplicate.

Data analysis. Scanned images were imported into the GenePix Pro 6.0 software (Axon; Molecular Devices, LLC) for grid alignment and data extraction. Replicated miRNAs were averaged, and miRNAs with intensities $\geq 30$ in all samples were chosen for use in calculating the normalization factor. Median normalization was used to normalize the expression data. After normalization, miRNAs with significant differences in expression were identified using volcano plot filtering. Hierarchical clustering was performed using MEV software (v4.6, TIGR; The J. Craig Venter Institute, La Jolla, CA, USA).

Group data are expressed as the mean \pm standard error of the mean. Statistical comparisons (performed using analysis of variance followed by Dunnett's post hoc test) were performed using Microsoft Excel 2007 (Microsoft Corp., Redmond, WA, USA). A two-tailed $\mathrm{P}<0.05$ was considered to indicate a statistically significant difference.

\section{Results}

RNA quantity and quality. The quantity and quality of the RNA samples in each group were checked by denaturing agarose gel electrophoresis and absorbance at $260 \mathrm{~nm}(\mathrm{~A} 260) / 280$ and A260/230 ratios (Fig. 1). The A260/280 ratio, A260/230 ratio and gel electrophoresis results confirmed that the quality of the RNA isolated was good.
Table III. miRNAs selected for bioinformatics analysis.

\begin{tabular}{lcc}
\hline Name & $\begin{array}{c}\text { Fold-change } \\
\text { (exp vs. con) }\end{array}$ & $\begin{array}{c}\text { P-value } \\
\text { (exp vs. con) }\end{array}$ \\
\hline hsa-miR-24-3p & 12.54569 & 0.02068 \\
hsa-miR-27b-3p & 12.24550 & 0.040829 \\
hsa-miR-720 & 10.49021 & 0.000145 \\
hsa-miR-205-5p & 12.08784 & 0.010106 \\
hsa-miR-1260b & 12.25486 & 0.011225 \\
hsa-miR-3676-5p & 15.98345 & 0.006023 \\
hsa-miR-5701 & 23.22485 & 0.049594 \\
hsa-miR-564 & 0.098898 & 0.036984 \\
hsa-miR-4799-3p & 0.099580 & 0.002004 \\
Down 3 & & \\
hsa-miR-4703-3p & 0.080486 & 0.003453 \\
\hline
\end{tabular}

exp, experimental; con, control; miR, microRNA; hsa, Homo sapiens.

Differential expression of miRNAs in NSCLP and control tissues. After normalization of the raw data, 254 miRNAs were found to be differentially expressed. Compared to the control, 181 miRNAs were found to be upregulated and 73 downregulated in the NCLP samples. Of these, based on fold-changes and P-values, 10 miRNAs were selected for further analysis, including 7 miRNAs that were upregulated (hsa-miR-24-3p, hsa-miR-27b-3p, hsa-miR-720, hsa-miR-205-5p, hsa-miR-1260b, hsa-miR-3676-5p and hsa-miR-5701) and 3 miRNAs that were downregulated (hsa-miR-564, hsa-miR-4799-3p and hsa-miR-4703-3p) (Table III).

miRNA target prediction and RT- $q P C R$ validation of microarray results. MicroCosm, Miranda and TargetScan were used to identify potential target genes for the dysregulated miRNAs. 
Table IV. Wnts associated with upregulated miRNAs.

\begin{tabular}{|c|c|c|c|c|c|}
\hline miRNA & Gene symbol & Miranda & MicroCosm & TargetScan & Num statistics \\
\hline hsa-miR-1260b & WNT1OB & 1 & 0 & 1 & 2 \\
\hline hsa-miR-1260b & WNT5A & 1 & 0 & 0 & 1 \\
\hline hsa-miR-1260b & $W N T 5 B$ & 1 & 0 & 0 & 1 \\
\hline hsa-miR-205-5p & WNT10A & 1 & 0 & 0 & 1 \\
\hline hsa-miR-205-5p & WNT5A & 1 & 1 & 0 & 2 \\
\hline hsa-miR-205-5p & WNT5B & 0 & 1 & 0 & 1 \\
\hline hsa-miR-205-5p & WNT9B & 0 & 1 & 0 & 1 \\
\hline hsa-miR-205-5p & WNT3 (NSF) & 1 & 0 & 1 & 2 \\
\hline hsa-miR-205-5p & AXIN2 & 1 & 0 & 1 & 2 \\
\hline hsa-miR-205-5p & SMAD4 & 1 & 0 & 1 & 2 \\
\hline hsa-miR-24-3p & WNT4 & 0 & 0 & 1 & 1 \\
\hline hsa-miR-24-3p & $W N T 8 B$ & 1 & 1 & 0 & 2 \\
\hline hsa-miR-24-3p & $G S K 3 B$ & 1 & 0 & 1 & 2 \\
\hline hsa-miR-27b-3p & $W N T 2 B$ & 1 & 0 & 0 & 1 \\
\hline hsa-miR-27b-3p & WNT3A & 0 & 1 & 1 & 2 \\
\hline hsa-miR-27b-3p & GOSR2 & 1 & 0 & 1 & 2 \\
\hline hsa-miR-27b-3p & SFRPI & 1 & 0 & 1 & 2 \\
\hline hsa-miR-27b-3p & $D K K 2$ & 1 & 0 & 1 & 2 \\
\hline hsa-miR-27b-3p & LRP5 & 1 & 1 & 0 & 2 \\
\hline hsa-miR-27b-3p & LRP6 & 1 & 0 & 1 & 2 \\
\hline hsa-miR-27b-3p & FZD7 & 1 & 0 & 1 & 2 \\
\hline hsa-miR720 & WNT5B & 1 & 0 & 0 & 1 \\
\hline
\end{tabular}

Classification: 0, potential target gene did not exist; 1, potential target gene existed in the database; 2, potential target gene existed in two databases. miR, microRNA; hsa, Homo sapiens; GSK3B, glycogen synthase kinase 3 $\beta$; GOSR2, golgi SNAP receptor complex member 2; SFRP1, secreted frizzled related protein 1; DKK2, dickkopf WNT signaling pathway inhibitor 2; LRP5, low-density lipoprotein receptor-related protein 5; FZD7, frizzled class receptor 7.

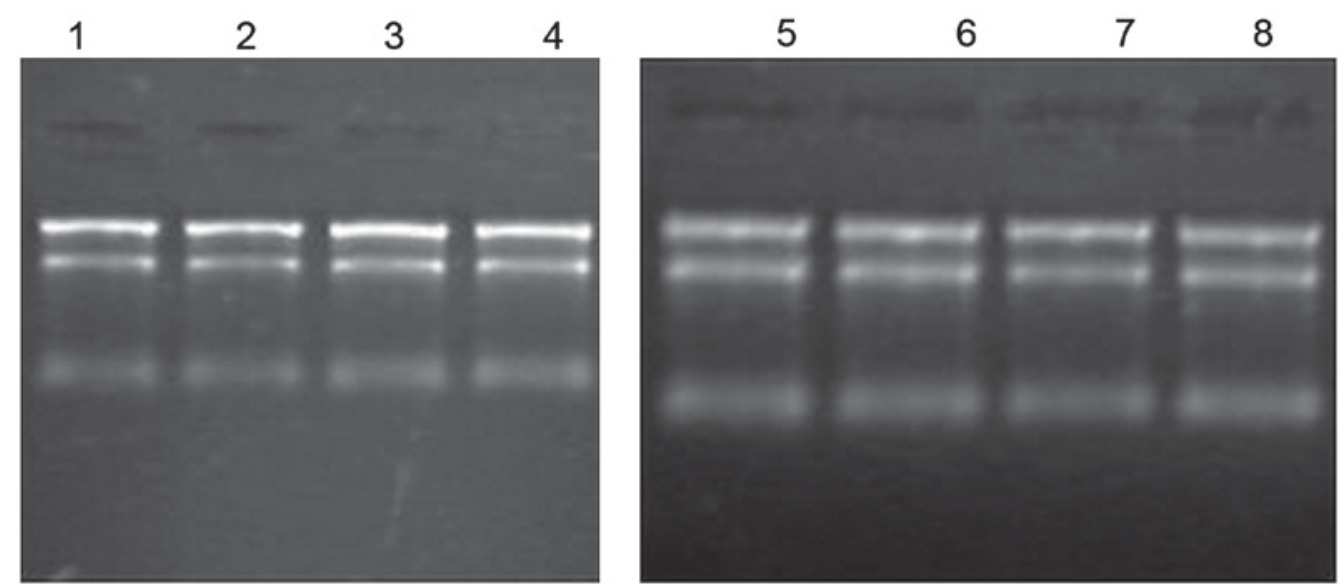

Figure 1. Determination of RNA integrity and genomic DNA contamination by denaturing agarose gel electrophoresis. Lanes: 1, total RNA from NSCLP sample 1; 2, total RNA from NSCLP sample 2; 3, total RNA from NSCLP sample 3; 4, total RNA from NSCLP sample 4; 5 , total RNA from control sample $1 ; 6$, total RNA from control sample $2 ; 7$, total RNA from control sample $3 ; 8$, total RNA from control sample 4 . NSCLP, nonsyndromic cleft lip with or without cleft palate.

The results revealed that hsa-miR-1260b, hsa-miR-205-5p, hsa-miR-24-3p, hsa-miR-27b-3p and hsa-miR720 may be associated with Wnt signaling genes, including WNT10B, WNT5A, WNT5B, WNT10A, WNT9B, WNT4, WNT8B, WNT2B, WNT3A, WNT3 (NSF), AXIN2, glycogen synthase kinase $3 \beta$ (GSK3B), golgi SNAP receptor complex member 2, secreted frizzled related protein 1 (SFRP1), dickkopf WNT signaling pathway inhibitor 2 (DKK2), low-density lipoprotein receptor-related protein (LRP)5, LRP6 and Frizzled class receptor 7 (Table IV). The dysregulation of hsa-miR-1260b, hsa-miR-205-5p, 

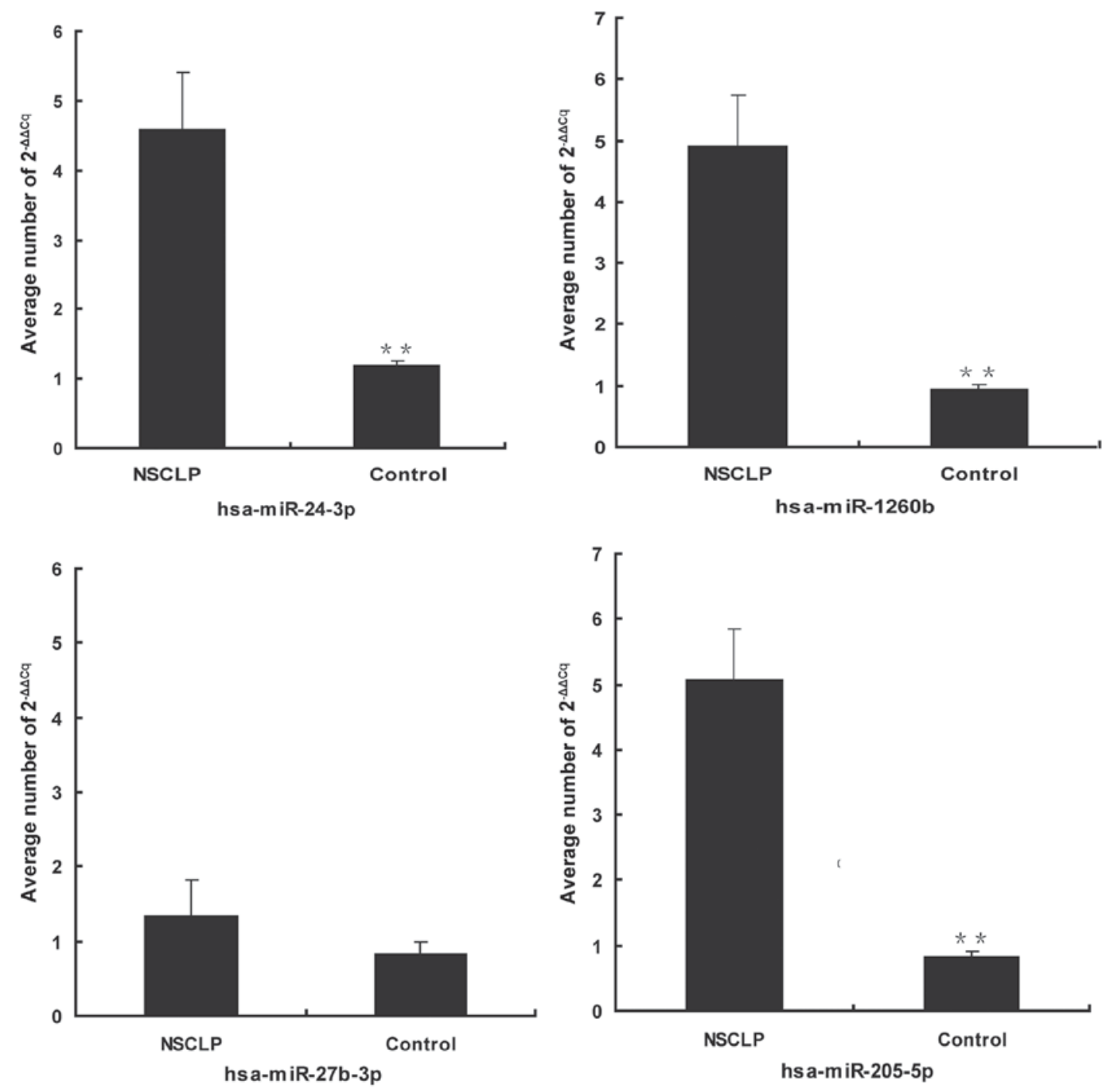

Figure 2. Confirmation of miRNA expression by PCR. PCR analysis confirmed the microarray results for three of the four miRNAs: hsa-miR-1260b, hsa-miR-205-5p and hsa-miR-24-3p were upregulated in NSCLP tissues; the difference in hsa-miR-27b-3p expression between NSCLP and control tissues was not statistically significant. The experiment was performed in triplicate. ${ }^{* *} \mathrm{P}<0.01$ vs. NSCLP. PCR, polymerase chain reaction; hsa, Homo sapiens; miR, microRNA; NSCLP, nonsyndromic cleft lip with or without cleft palate; $\mathrm{Cq}$, fractional cycle number at which the fluorescence passes the fixed threshold.

hsa-miR-24-3p and hsa-miR-27b-3p, for which predicted target information was supported by information from at least two or more databases, was confirmed by RT-qPCR. The results of the RT-qPCR analysis were consistent with the microarray data for three of the four miRNAs examined and showed that, although expression of hsa-miR-27b-3p was not significantly different between NSCLP and control $(\mathrm{P}=0.09)$, hsa-miR-1260b ( $\mathrm{P}=0.001)$, hsa-miR-205-5p $(\mathrm{P}=0.001)$ and hsa-miR-24-3p $(\mathrm{P}=0.003)$ were significantly upregulated in NSCLP tissues (Fig. 2).

\section{Discussion}

The present study detected 254 miRNAs that were differentially expressed in NSCLP tissues as compared to those in normal umbilical cord tissues. The NSCLP miRNA signature revealed an altered biological phenotype that is similar to the miRNA profiles of various growth-associated diseases: It was characterized by significant upregulation of miRNAs (181/254). Based on fold-change and P-values, 10 of these
miRNAs, including 8 hsa-miRNAs that were upregulated and 2 hsa-miRNAs that were downregulated, were selected for further analysis. Of note, hsa-miR-27b-3p, hsa-miR-720, hsa-miR-1260b, hsa-miR-24-3p and hsa-miR-205-5p were found to be highly expressed in tissues from NSCLP patients. Furthermore, bioinformatics analysis showed that various Wnt genes such as $W N T 2 B$ and $W N T 10 B$ were associated with these hsa-miRNAs that we screened. Accordingly, various miRNAs in control and NSCLP tissues were identified by RT-qPCR, including hsa-miR-720, hsa-miR-1260b, hsa-miR-24-3p and hsa-miR-205-5p.

A growing body of evidence showed that the Wnt family of genes and their associated signaling pathways have critical roles in various processes of growth and development, including embryonic induction, epithelial and mesenchymal cellular polarity, cell fate determination, cytoskeletal organization and cell proliferation (22-24). Wnt expression is observed in the upper lip and primary and secondary palates, and Wnts are involved in regional specification of the vertebrate face. 
WNT4, targeted by hsa-miR-24-3p (25), is a member of the canonical Wnt signaling pathway and is extensively expressed in palatal epithelium. He et al (26) found that WNT4 is expressed in the palatal epithelium in the anterior as well as posterior palate in a microarray survey of gene expression profile in E13.5 mouse palatal shelves. Yu et al (27) demonstrated miR-205 suppresses the expression of GSK-3 $\beta$, the protein encoded by $G S K 3 B$, through binding to its 3'-untranslated region. It has been shown that GSK-3 $\beta$ is a direct target of miR-205 in 3T3-L1 cells and suppression of the expression of GSK-3 $\beta$ by miR-205 led to activation of the Wnt pathway. $G S K 3 B$ is part of the Wnt signaling pathway and has a major role in epithelial cell homeostasis (28). A role for $G S K 3 B$ in craniofacial defects has also been demonstrated, since homozygous null mice display incomplete fusion of the ribs at the midline and bifid sternum, delayed sternal ossification and cleft palate (29).

However, no direct evidence has illustrated how miR-1260b regulates Wnt genes and affects lip fusion and palatal fusion. Hirata et al (30) found that miRNA-1260b can silence SFRPI, $D K K 2$ and SMAD4 genes, which affects cancer cell proliferation and invasion as well as the percentage of apoptotic cells. Iwata et al (31) revealed that $\mathrm{Smad} 4$ can synergistically regulate the fate of the medial edge epithelium during palatal fusion in mice. Accordingly, it was speculated that miRNA-1260b may also regulate other genes associated with orofacial clefts.

In fact, individuals born with a cleft have a higher mortality rates at all stages of life (32). Individuals with a cleft as well as their family members also have a higher risk of developing various cancer types. Andrade Filho et al (33) found that GSK-3 $\beta$ and Axin2 belong to the Wnt pathway and increase susceptibility to oral squamous cell carcinoma and colon cancer, respectively. The present study showed that hsa-miR-205-5p and hsa-miR-24-3p regulates the levels of GSK-3 $\beta$ and Axin2. Axin2 is a negative regulator of Wnt- $\beta$-catenin, which has a critical and evolutionarily conserved role in directing cell fate during craniofacial morphogenesis, and Axin2 mRNA is expressed throughout palatogenesis stages (34).

As Wnt-regulating miRNAs were found to be associated with NSCLP in the present study for the first time, they hold potential value for further research on the association of miRNAs with NSCLP. Wnt5A deficiency has been found to lead to a complete cleft of the secondary palate, which exhibits distinct phenotypic alterations at the histological, cellular and molecular level in the anterior as well as posterior regions (35). Alterations in Wnt5A function may perturb formation and/or fusion of the facial processes and predispose to NSCLP (36). $W N T 9 B$ may also be involved in the clefting phenotype and is therefore an excellent candidate gene for NSCLP. Wnt9b can activate the $\mathrm{Wnt} / \beta$-catenin response in first branchial arch mesenchyme. When A/WySn mice were bred with $\mathrm{WNT} \mathrm{B}^{-/-}$mice, there was a higher prevalence of clefting in the progeny $(67 \%)$ than in the founders (37). WNT10A and $W N T 10 B$ have not previously been identified as being associated with NSCLP. However, Lin et al (38) showed that WNT1Oa and WNT1Ob transcripts in palatal epithelium were involved in the formation of palatal rugae, with Wnt10a being more strongly expressed in the rugae. Although it has not yet been determined whether $W N T 8 B$ and $W N T 5 B$ are directly involved in NSCLP, Kawakami et al (39) found that limb bud formation was initiated by Wnt molecules (Wnt2b and Wnt8), which are expressed in the lateral plate mesoderm and which signal through $\beta$-catenin to restrict fibroblast growth factor 10 expression in the presumptive limb mesoderm. Kim et al (40) also showed that Wnt8b can suppress Frizzled 8a expression in the anterior neuroectoderm and potentially affect the level and/or range of Wnt signaling.

In the present study, hsa-miR-27b-3p was also identified by microarray analysis as being upregulated in NSCLP, although the RT-qPCR results indicated that the difference between NSCLP and control tissues was not significant $(\mathrm{P}=0.09)$. However, its involvement in NSCLP cannot be ruled out until more samples are collected and tested.

It should be noted that the present study only revealed a disparity in the expression of miRNAs, which may be associated with the Wnt family of genes and the associated signaling pathways, between 4 NSCLP tissue samples and 4 normal umbilical cord samples. One of the limitations of the present study is the relatively modest number of NSCLP cases examined, which may explain certain results. It remains to be determined whether the miRNAs identified in the present study actually perturb the Wnt signaling pathway, even though bioinformatics support this hypothesis. In the future, a larger number of samples should be collected and tested in a follow-up study to elucidate the various factors that contribute to NSCLP.

\section{Acknowledgements}

This study was supported by grants from the Li Ka Shing Foundation.

\section{References}

1. Meng T, Shi B, Zheng Q, Wang Y and Li S: Clinical and epidemiologic studies of nonsyndromic cleft lip and palate in china: Analysis of 4268 cases. Ann Plast Surg 57: 264-269, 2006.

2. Maestri NE, Beaty TH, Hetmanski J, Smith EA, McIntosh I, Wyszynski DF, Liang KY, Duffy DL and VanderKolk C: Application of transmission disequilibrium tests to nonsyndromic oral clefts: Including candidate genes and environmental exposures in the models. Am J Med Genet 73: 337-344, 1997.

3. Schliekelman P and Slatkin M: Multiplex relative risk and estimation of the number of loci underlying an inherited disease. Am J Hum Genet 71: 1369-1385, 2002.

4. Wyszynski DF, Duffy DL and Beaty TH: Maternal cigarette smoking and oral clefts: A meta-analysis. Cleft Palate Craniofac J 34: 206-210, 1997.

5. Lidral AC and Moreno LM: Progress toward discerning the genetics of cleft lip. Curr Opin Pediatr 17: 731-739, 2005.

6. Lidral AC and Murray JC: Genetic approaches to identify disease genes for birth defects with cleft lip/palate as a model. Birth Defects Res A Clin Mol Teratol 70: 893-901, 2004.

7. Shi M, Wehby GL and Murray JC: Review on genetic variants and maternal smoking in the etiology of oral clefts and other birth defects. Birth Defects Res C Embryo Today 84: 16-29, 2008.

8. Bernstein E, Kim SY, Carmell MA, Murchison EP, Alcorn H, Li MZ, Mills AA, Elledge SJ, Anderson KV and Hannon GJ: Dicer is essential for mouse development. Nat Genet 35: 215-217, 2003.

9. Chen JF, Murchison EP, Tang R, Callis TE, Tatsuguchi M, Deng Z, Rojas M, Hammond SM, Schneider MD, Selzman CH, et al: Targeted deletion of Dicer in the heart leads to dilated cardiomyopathy and heart failure. Proc Natl Acad Sci USA 105: 2111-2116, 2008.

10. Murchison EP, Stein P, Xuan Z, Pan H, Zhang MQ, Schultz RM and Hannon GJ: Critical roles for Dicer in the female germline. Genes Dev 21: 682-693, 2007. 
11. Shalgi R, Brosh R, Oren M, Pilpel Y and Rotter V: Coupling transcriptional and post-transcriptional miRNA regulation in the control of cell fate. Aging (Albany NY) 1: 762-770, 2009.

12. Alvarez-Garcia I and Miska EA: MicroRNA functions in animal development and human disease. Development 132: 4653-4662, 2005.

13. Wienholds E, Koudijs MJ, van Eeden FJ, Cuppen E and Plasterk RH: The microRNA-producing enzyme Dicer1 is essential for zebrafish development. Nat Genet 35: 217-218, 2003.

14. Eberhart JK, He X, Swartz ME, Yan YL, Song H, Boling TC, Kunerth AK, Walker MB, Kimmel CB and Postlethwait JH: MicroRNA Mirn140 modulates Pdgf signaling during palatogenesis. Nat Genet 40: 290-298, 2008

15. Hornstein E and Shomron N: Canalization of development by microRNAs. Nat Genet 38 (Suppl): S20-S24, 2006.

16. Lee CT, Risom T and Strauss WM: MicroRNAs in mammalian development. Birth Defects Res C Embryo Today 78: 129-139, 2006.

17. Shalgi R, Lieber D, Oren M and Pilpel Y: Global and local architecture of the mammalian microRNA-transcription factor regulatory network. PLoS Comput Biol 3: e131, 2007.

18. Song L and Tuan RS: MicroRNAs and cell differentiation in mammalian development. Birth Defects Res C Embryo Today 78: 140-149, 2006

19. Qiu WL: Oral and maxillofacial surgery. In: Congenital cleft lip, facial cleft and palate cleft. 4th edition. Beijing People's Medical Publishing House Press, Beijing, p369, 2000.

20. Qiu WL: Oral and maxillofacial surgery. In: Congenital cleft lip, facial cleft and palate cleft. 4th edition. Beijing People's Medical Publishing House Press, Beijing, pp374-398, 2000.

21. Livak KJ and Schmittgen TD: Analysis of relative gene expression data using real-time quantitative PCR and the 2(-Delta Delta C(T)) Method. Methods 25: 402-408, 2001.

22. Cadigan KM and Nusse R: Wnt signaling: A common theme in animal development. Genes Dev 11: 3286-3305, 1997.

23. Bejsovec A: Wnt pathway activation: New relations and locations. Cell 120: 11-14, 2005.

24. Dale RM, Sisson BE and Topczewski J: The emerging role of Wnt/PCP signaling in organ formation. Zebrafish 6: 9-14, 2009.

25. Chhabra R, Dubey R and Saini N: Cooperative and individualistic functions of the microRNAs in the miR-23a 27a 24-2 cluster and its implication inhuman diseases. Mol Cancer 9: 232, 2010.

26. He F, Xiong W, Wang Y, Li L, Liu C, Yamagami T, Taketo MM, Zhou $\mathrm{C}$ and Chen Y: Epithelial Wnt/ $\beta$-catenin signaling regulates palatal shelf fusion through regulation of Tgf $\beta 3$ expression. Dev Biol 350: 511-519, 2011.

27. Yu J, Chen Y, Qin L, Cheng L, Ren G, Cong P, Mo D and He Z: Effect of miR-205 on 3T3-L1 preadipocyte differentiation through targeting to glycogen synthase kinase 3 beta. Biotechnol Lett 36: 1233-1243, 2014.

28. Kim M, Datta A, Brakeman P, Yu W and Mostov KE: Polarity proteins PAR6 and aPKC regulate cell death through GSK-3beta in 3D epithelial morphogenesis. J Cell Sci 120: 2309-2317, 2007.
29. Liu KJ, Arron JR, Stankunas K, Crabtree GR and Longaker MT: Chemical rescue of cleft palate and midline defects in conditional GSK-3beta mice. Nature 446: 79-82, 2007.

30. Hirata H, Ueno K, Nakajima K, Tabatabai ZL, Hinoda Y, Ishii N and Dahiya R: Genistein downregulates onco-miR-1260b and inhibits Wnt-signalling in renal cancer cells. Br J Cancer 108: 2070-2078, 2013.

31. Iwata J, Suzuki A, Pelikan RC, Ho TV, Sanchez-Lara PA, Urata M, Dixon MJ and Chai Y: Smad4-Irf6 genetic interaction and TGF $\beta$-mediated IRF6 signaling cascade are crucial for palatal fusion in mice. Development 140: 1220-1230, 2013.

32. Christensen K, Juel K, Herskind AM and Murray JC: Long term follow up study of survival associated with cleft lip and palate at birth. BMJ 328: 1405, 2004.

33. Andrade Filho PA, Letra A, Cramer A, Prasad JL, Garlet GP, Vieira AR, Ferris RL and Menezes R: Insights from studies with oral cleft genes suggest associations between WNT-pathway genes and risk of oral cancer. J Dent Res 90: 740-746, 2011.

34. Parr BA, Shea MJ, Vassileva G and McMahon AP: Mouse Wnt genes exhibit discrete domains of expression in the early embryonic CNS and limb buds. Development 119: 247-261, 1993.

35. He F, Xiong W, Yu X, Espinoza-Lewis R, Liu C, Gu S, Nishita M, Suzuki K, Yamada G, Minami Y and Chen Y: Wnt5a regulates directional cell migration and cell proliferation via Ror2-mediated noncanonical pathway in mammalian palate development. Development 135: 3871-3879, 2008.

36. Chiquet BT, Blanton SH, Burt A, Ma D, Stal S, Mulliken JB and Hecht JT: Variation in WNT genes is associated with non-syndromic cleft lip with or without cleft palate. Hum Mol Genet 17: 2212-2218, 2008

37. Juriloff DM, Harris MJ, McMahon AP, Carroll TJ and Lidral AC: Wnt9b is the mutated gene involved in multifactorial nonsyndromic cleft lip with or without cleft palate in $\mathrm{A} / \mathrm{WySn}$ mice, as confirmed by a genetic complementation test. Birth Defects Res A Clin Mol Teratol 76: 574-579, 2006.

38. Lin C, Fisher AV, Yin Y, Maruyama T, Veith GM, Dhandha M, Huang GJ, Hsu W and Ma L: The inductive role of Wnt- $\beta$-Catenin signaling in the formation of oral apparatus. Dev Biol 356: 40-50, 2011.

39. Kawakami Y, Capdevila J, Büscher D, Itoh T, Rodríguez Esteban C and Izpisúa Belmonte JC: WNT signals control FGF-dependent limb initiation and AER induction in the chick embryo. Cell 104: 891-900, 2001.

40. Kim SH, Shin J, Park HC, Yeo SY, Hong SK, Han S, Rhee M, Kim CH, Chitnis AB and Huh TL: Specification of an anterior neuroectoderm patterning by Frizzled8a-mediated Wnt8b signalling during late gastrulation in zebrafish. Development 129: 4443-4455, 2002. 